\title{
Blurring Boundaries: Carnap, Quine, and the Internal-External Distinction
}

\author{
Sander Verhaegh ${ }^{1}$
}

Received: 20 February 2016/Accepted: 6 October 2016/Published online: 13 October 2016

(C) The Author(s) 2016. This article is published with open access at Springerlink.com

\begin{abstract}
Quine is routinely perceived as saving metaphysics from Carnapian positivism. Where Carnap rejects metaphysical existence claims as meaningless, Quine is taken to restore their intelligibility by dismantling the former's internalexternal distinction. The problem with this picture, however, is that it does not sit well with the fact that Quine, on many occasions, has argued that metaphysical existence claims ought to be dismissed. Setting aside the hypothesis that Quine's metaphysical position is incoherent, one has to conclude that his views on metaphysics are subtler than is often presupposed; both the received view that Quine saved metaphysics and the opposite view that Carnap and Quine are on the same anti-metaphysical team seem too one-sided if we take seriously Quine's own pronouncements on the issue. In this paper, I offer a detailed reconstruction of Quine's perspective on metaphysical existence claims. Scrutinizing his published work as well as unpublished papers, letters, and notebooks, I show how Quine is able to both blur the boundary between scientific sense and metaphysical nonsense and to argue that we cannot ask what reality is really like in a distinctively philosophical way. I argue that although Quine's position is much closer to Carnap's than the received view suggests, it still differs in two crucial respects.
\end{abstract}

\section{Introduction}

Most metaphysicians agree that we should not rest content with our ordinary ascriptions of existence. Although in everyday life and in the sciences we may freely talk about elephants, electrons, and empty sets, as philosophers we must

Sander Verhaegh

A.A.Verhaegh@uvt.nl

1 Tilburg Center for Logic, Ethics, and Philosophy of Science (TiLPS), Tilburg University, Dante Building (Second Floor), Warandelaan 2, 5037 AB Tilburg, The Netherlands 
investigate whether these objects really exist. ${ }^{1}$ Carnap, as is well known, argues that these philosophical questions of existence are devoid of cognitive content. In his seminal "Empiricism, Semantics, and Ontology" (ESO), he argues that existence claims only make sense internal to a linguistic framework and that we cannot ask whether an entity is 'real' in an (external) framework-independent way; 'reality' itself is a concept internal to a framework and as such "cannot be meaningfully applied to the [framework] itself" (1950, 207). Instead, Carnap proposes to reinterpret metaphysical questions as practical questions about which frameworks scientists ought to adopt.

Quine believes that Carnap's strict distinction between internal and external questions cannot be maintained. According to Quine, no question is purely theoretical or purely practical; just like one's decision to adapt a hypothesis in the light of new experiential data, one's decision to adopt a certain framework will be informed by both theoretical knowledge and pragmatic criteria. The question whether or not to accept a certain entity as 'real' therefore is a meaningful question that can be answered by ordinary scientific means. Ontological questions, in other words, are "on a par with questions of natural science" (1951a, 211).

This little stick-figure summary of the Carnap-Quine debate suggests that Quine breathed new life into the metaphysical project that was deemed meaningless by Carnap and his fellow positivists. For where Carnap rejects philosophical existence claims as meaningless, Quine seems to restore their intelligibility by dismantling the former's internal-external distinction. Indeed, this seems to be Quine's own perspective on his debate with Carnap:

I think the positivists were mistaken when they despaired of existence [...] and accordingly tried to draw up boundaries that would exclude such sentences as meaningless. Existence statements in this philosophical vein do admit of evidence, in the sense that we can have reasons, and essentially scientific reasons, for including numbers or classes or the like in the range of values of our variables. (1968, 97, my emphasis)

When quantifying over a class of entities is indispensable for the formulation of our best scientific theories, Quine argues, we are to countenance these entities as real. As a result, Quine blurs the "boundary between scientific sense and metaphysical nonsense" (1987a, 144) and concludes that Carnap and his positivistic comrades were simply "wrong if and when they concluded that the world is not really composed of atoms or whatever" (1992, 405).

The picture that Quine revived the legitimacy of philosophical existence claims is often defended in the literature as well. In his introduction to the history of analytic philosophy, for example, Avrum Stroll argues that Quine blurs "the boundary between speculative metaphysics and science, thus giving a kind of credibility to metaphysics that Carnap would never have countenanced" (2000, 200). Similarly, Nicholas Joll claims that "Quine saves metaphysics from positivism" (2010) and

\footnotetext{
1 See, for example, Berto and Plebani $(2015,8)$ : "Mathematicians talk about prime numbers; biologists talk about cross-fertile biological species; astrophysicists deal with solar flares. But, qua scientists, they will not typically wonder whether there are really prime numbers, species, properties or events".
} 
Stephen Yablo argues that Quine, unlike Carnap, provides us with a way to attach "believable truth values to philosophical existence claims" $(1998,259){ }^{2}$

Yet, there is something puzzling about this picture. For it does not sit well with the fact that Quine, on many occasions, does seem to argue against the intelligibility of metaphysical existence claims. Quine has argued, for example, that he is "[n]o champion of traditional metaphysics" (1951a, 204) and that the question "what reality is really like [...] is self-stultifying" $(1992,405)$. On a few occasions, Quine even argues that the "[p]ositivists were right in branding such metaphysics as meaningless" (ibid.). ${ }^{3}$ Even more surprising from the above sketched perspective is that Quine often appeals to the very same argument Carnap gives in ESO, viz. the argument that the notion of 'reality' cannot be legitimately applied outside the system of which it is an element. We simply "cannot significantly question the reality of the external world", Quine argues, "for to do so is simply to dissociate the [term] 'reality' [...] from the very applications which originally did most to invest [this term] with whatever intelligibility [it] may have for us" (1954b, 229).

Setting aside the hypothesis that Quine's metaphysical position is incoherent, one has to conclude that his views on metaphysics are subtler than has often been presupposed; both the received view that Quine restored the intelligibility of metaphysics by dismantling Carnap's internal-external distinction and the opposite position that "[f]or all practical purposes, Quine does agree with Carnap about the status of metaphysical issues" (Price 2007, 391) are too one-sided if we take seriously Quine's own pronouncements on the issue. ${ }^{4}$ As of yet, however, little work has been devoted to spelling out the exact details of Quine's perspective on the status of metaphysical existence claims.

In this paper, I offer a first attempt to show how Quine is able to both blur the boundary between "natural science" and the "philosophical effusions that Carnap denounced under the name of metaphysics" (1984, 127-128) and to argue that it is self-stultifying to ask what reality is really like' $(1992,405) .{ }^{5}$ What I offer, then, is a detailed historical reconstruction of Quine's perspective on metaphysical existence claims. I show that although Quine's position is much closer to Carnap's than the

\footnotetext{
${ }^{2}$ Price $(2007,380)$ aptly summarizes the above perspective on the Carnap-Quine debate by claiming that Quine is traditionally regarded as "the savior of a more robust metaphysics" by driving "a stake through the heart of ESO, [...] thus [dispatching] the last incarnation of the Viennese menace". See also Eklund (2013, 229), who argues that the above perspective also dominates contemporary debates in metaontology. Alspector-Kelly (2001) and Price (2007, 2009) are exceptions to the received view; they were the first to suggest that the standard conception of the Carnap-Quine debate is misguided.

3 See also, for example, Quine (1986b, 337): "if some scientifically undigested terms of metaphysics [...] were admitted into science along with all their pertinent doctrine [...] [i]t would be an abandonment of the scientists' quest for economy and of the empiricists' standard of meaningfulness".

4 To be fair, Price does not aim to provide a complete and detailed interpretation of Quine's view on metaphysics. Rather, his main aim is to show that Quine's "position on ontological commitment [...] favors, or at least leaves open, a view much closer to that of Carnap" (Ibid., 378, my emphasis).

5 In doing so, I will rely significantly on unpublished notes, drafts, and lectures that are stored at the W. V. Quine Papers at Houghton Library. For where Quine's published work on metaphysics, especially his discussions of Carnap's view, is mostly concerned with ontology narrowly conceived, the Houghton archives, as we shall see, contain a wealth of unpublished material in which he reflects more broadly on the nature of metaphysics. In transcribing Quine's autograph notes, drafts, and lectures, I have aimed to minimize editorial interference and chosen not to correct ungrammatical shorthand.
} 
received view suggests, it still differs from the latter's position in two crucial respects. This paper will be structured as follows. After introducing Carnap's position in ESO as well as Quine's arguments against the former's position (Sect. 2), I argue that the standard interpretation of Quine's views is incorrect because it rests on an equivocation between two different internal-external distinctions (Sect. 3). Next, I show that although Quine rejects both these distinctions, he agrees with Carnap that metaphysical existence claims ought to be dismissed (Sect. 4). Finally, I argue that although Quine is as sceptical as Carnap about metaphysical existence claims, there is still a significant difference between the two because they fundamentally disagree about why such claims ought to be dismissed (Sect. 5).

\section{Internal and External Existence Claims}

Carnap's problems with philosophical existence claims are deep-rooted. Already in his pre-Vienna period, he considered metaphysical disputes to be "sterile and useless" (1963a, 44). Influenced by the early Wittgenstein, Carnap developed the view that metaphysical theses are without cognitive content, arguing that they are pseudo-sentences because they "cannot in principle be supported by an experience" $(1928,328)$. Where metaphysicians will usually agree about whether or not a certain entity is real in an everyday empirical sense, they rely on a "nonempirical (metaphysical) concept of reality" when they are involved in a philosophical dispute (ibid., 340).

Although Carnap has never felt any qualms about these early arguments against metaphysics, ${ }^{6}$ he later felt the need to return to the subject and explain his position once more. Carnap wrote ESO in response to critical empiricists who objected that he referred to abstract objects without having shown that they "actually exist" and argued that these empiricists "[neglect] the fundamental distinction" between ordinary and philosophical ascriptions of existence (1963a, 65-66). ${ }^{7}$

It is in ESO that Carnap differentiates between internal and external questions in order to capture this distinction. Ordinary questions of existence with respect to, for example, numbers or physical things, Carnap argues, should be viewed as questions internal to linguistic frameworks containing the rules for our use of the concepts 'number' and 'physical thing'. Philosophical questions of existence about numbers and physical things, on the other hand, are to be viewed as external questions asked prior to the adoption of any such framework. These latter questions are the questions that Carnap's fellow empiricists had in mind when they questioned whether Carnap is justified in using a framework that quantifies over abstract objects without having shown that they actually exist. According to Carnap, however, such external questions are meaningless. For, and here his argument is similar to the one

\footnotetext{
${ }^{6}$ See Carnap's (1950, 215) and (1963b, 870).

7 See Alspector-Kelly (2001) for a more detailed discussion of Carnap's motives in ESO. As the present paper deals with Quine's ideas about metaphysics, I will mostly limit myself to a discussion of Quine's interpretation of Carnap, acknowledging that this reading might not do justice to the historical Carnap.
} 
developed in his early work, the very concept of 'reality' appealed to in metaphysical questions cannot be given a meaningful interpretation:

The concept of reality occurring in [...] internal questions is an empirical, scientific, non-metaphysical concept. To recognize something as a real thing or event means to succeed in incorporating it into the system of things [...] according to the rules of the framework. From these questions we must distinguish the external question of the reality of the thing world itself. In contrast to the former questions, this question is [...] framed in a wrong way. To be real in the scientific sense means to be an element of the system; hence this concept cannot be meaningfully applied to the system itself. $(1950,207)$

Concepts, according to Carnap, only make sense in as far as the rules for their use are specified within a framework. As a result, the concept of 'reality' itself will only make sense within a linguistic framework and hence philosophers fail "in giving to the external question and to the possible answers any cognitive content" (ibid., 209). ${ }^{8}$

Because external questions fail to be meaningful when interpreted as theoretical, Carnap proposes that we should view them as practical questions, as matters "of practical decision concerning the structure of our language" (ibid., 207). Rather than asking whether or not a certain entity $x$ really exists, we should ask whether or not it is useful to adopt one or another $x$-related framework, a question that will be guided by pragmatic criteria. According to Carnap,

the introduction of [a] framework is legitimate in any case. Whether or not this introduction is advisable for certain purposes is a practical question of language engineering, to be decided on the basis of convenience, fruitfulness, simplicity, and the like. (1963a, 66)

As a result, although Carnap considers external questions to be devoid of cognitive content, such questions can still be given "a meaning by reinterpreting them or, more exactly, by replacing them with the practical questions concerning the choice of certain language forms" (Carnap 1963b, 869). Carnap's internal-external distinction, in short, becomes a distinction between the theoretical and the practical when external questions are reinterpreted as questions about whether or not to adopt a certain framework.

Quine rejects Carnap's distinction between the internal and the external. In fact, he develops two arguments against the distinction: one in which he reduces it to the analytic-synthetic divide, and one in which he argues that both internal and external statements are partly theoretical and partly practical in nature. ${ }^{9}$ Quine's first

\footnotetext{
${ }^{8}$ Of course, Carnap's argument with respect to the concept of 'reality' applies equally to philosophical notions that serve the same function. In their metaphysical inquiries, Carnap argues, philosophers might also talk about "subsistence" or the "ontological status" of an entity. These alternative philosophical notions, however, are also without content because philosophers have failed to explain their use "in terms of the common scientific language" (ibid., 209).

9 Quine develops these arguments in "Two Dogmas of Empiricism” (1951b, 45-46), “On Carnap's Views on Ontology" (1951a), and "Carnap and Logical Truth" (1954a, 132). In the second essay, Quine also provides a third argument against Carnap's distinction by reducing it to a dichotomy between
} 
argument is largely negative. He argues that "a double standard for ontological questions and scientific hypotheses" requires "an absolute distinction between the analytic and the synthetic", a distinction which he famously argues to be untenable (1951b, 43-44). ${ }^{10}$ Quine's second argument is more positive, and is based on his constructive "empiricism without the dogmas" (1951b, §6). If, as Quine maintains, science is a unified structure whose statements face experience only in clusters such that no statement is in principle immune to revision, then all statements that are relevant to science, including Carnap's linguistic proposals, will be guided by both theoretical and practical concerns. Just like the decision to adapt a hypothesis in the light of new experiential data, one's decision to adopt a certain framework will be informed by theoretical as well as practical considerations:

The differences here are in my view differences only in degree and not in kind. [...] Carnap maintains that ontological questions [...] are questions not of fact but of choosing a convenient conceptual scheme or framework for science; and with this I agree only if the same be conceded for every scientific hypothesis. (1951a, 211)

Quine, in sum, dissolves Carnap's internal-external distinction; first by arguing that it relies on the untenable analytic-synthetic divide, and second by arguing that a more realistic model of theory change construes all revisions as guided by both theoretical and practical considerations. In arguing that the difference between scientific and ontological claims is only gradual, Quine therefore seems to blur the boundary between metaphysics and science, a boundary that Carnap had propagated in order to dismiss metaphysics as meaningless.

\section{Two Distinctions}

The question whether or not Quine's arguments effectively undermine Carnap's internal-external distinction has been a matter of some controversy. ${ }^{11}$ In what follows, however, I limit my discussion to a more specific, yet not entirely unrelated

Footnote 9 continued

category and subclass questions. According to Quine, external questions are concerned with the existence of entities expressed by a category word (e.g. 'Are there things?' or 'Are there numbers?'), whereas internal questions are concerned with the existence of subclasses of them (e.g. 'Are there rabbits?' or 'Are there prime numbers between 10 and 20?'). He then argues that the latter distinction is trivial, because "there is no evident standard of what to count as a category" $(1968,92)$. As several scholars have noted, however, Quine's argument here misses the mark because the distinction between internal and external questions of existence cannot be based on the category-subclass distinction; category as well as subclass questions can be asked in both an internal and an external vein. In later work, Quine is somewhat more careful in his reading of Carnap when he describes the latter's ideas about category words (Allwörter) and the related category-subclass distinction as "an early doctrine of Carnap" (1968, 91, my emphasis), explicitly referring only to the latter's The Logical Syntax of Language (1934, §76), not to ESO.

${ }^{10}$ Carnap himself also seems to have appreciated the close relation between the internal-external distinction on the one hand, and the analytic-synthetic distinction on the other. See Carnap (1950, 215n5).

11 See Haack (1976, §3), Bird (1995), and Glock (2002, §5) for a critical evaluation of Quine's arguments. Yablo $(1998, \S \S 5-7)$ and Gallois $(1998, \S 2)$, on the other hand, yield a more positive verdict. 
issue, viz. the question what type of internal-external distinction Quine aimed to undermine. I argue that we ought to differentiate between two types of internalexternal distinctions and that Quine's arguments apply to only one of them.

As we have seen in the previous section, Carnap differentiates three types of questions of existence depending on whether we are concerned with the metaphysician's perspective or with Carnap's practical reinterpretation:

(I) Internal questions about the existence or reality of a certain kind of entities, asked after the adoption of a linguistic framework

$\left(\mathrm{E}_{1}\right)$ External questions about the existence or reality of a certain kind of entities, asked before the adoption of a linguistic framework

$\left(\mathrm{E}_{2}\right)$ External questions about whether or not it is advisable to adopt a particular linguistic framework

Although it is generally recognized that Carnap distinguishes between three types of questions, ${ }^{12} E_{1}$ and $E_{2}$-questions are often conflated under the general heading 'external questions' in discussions about the Carnap-Quine debate. As a result, some have failed to realize that we cannot speak about 'the internal-external distinction' in general. That is, scholars often ignore the fact that ESO contains two such distinctions, depending on what type of external question one is talking about:

$\left(\mathrm{I} / \mathrm{E}_{1}\right) \quad$ A distinction between meaningful internal questions and metaphysical external questions without cognitive content

$\left(\mathrm{I} / \mathrm{E}_{2}\right) \quad$ A distinction between internal questions of a theoretical and external questions of a practical nature

$\mathrm{I} / \mathrm{E}_{1}$ primarily distinguishes between the meaningful and the meaningless, whereas the $\mathrm{I} / \mathrm{E}_{2}$-distinction emphasizes the difference between questions of a theoretical and questions of a practical nature.

Now, consider the question whether Quine was attacking $I / E_{1}$ or $I / E_{2}$. If one believes that Quine, in criticizing the internal-external distinction, aimed to revive metaphysical existence claims, one clearly presupposes that Quine was attacking $\mathrm{I} / \mathrm{E}_{1} \cdot{ }^{13}$ For if Quine had really aimed to breathe new life into the metaphysical project that was deemed meaningless by Carnap, he would have tried to show that the distinction between I-questions and $E_{1}$-questions should not be viewed as a distinction between the meaningful and the meaningless. He would have tried to show, in other words, that Carnap's $\mathrm{E}_{1}$-questions can be given "a clear cognitive interpretation" or can be given "a formulation [...] in terms of the common scientific language" (Carnap 1950, 209).

Yet Quine does not seem to be concerned with anything like this at all. Rather, as we shall see, there are many reasons for thinking that he was concerned with undermining not $\mathrm{I} / \mathrm{E}_{1}$ but $\mathrm{I} / \mathrm{E}_{2} .{ }^{14}$ Quine's arguments against Carnap's distinction

\footnotetext{
12 See, for example, Eklund (2013, 237): "Carnap is actually drawing a tripartite distinction: between questions internal to a framework, questions about which framework we should choose to employ, and the pseudo-questions".

13 See, for example Haack $(1976, \S 3.1)$ and Bird $(1995, \S 2)$, where Quine's arguments are evaluated in terms of their effectiveness in undermining $\mathrm{I} / \mathrm{E}_{1}$.

14 Eklund (2013) correctly suggests that Quine attacks $\mathrm{I} / \mathrm{E}_{2}$, although he does not argue for this claim.
} 
provide the first reason. Recall that Quine first reduces the internal-external distinction to the analytic-synthetic divide and then argues that both scientific hypotheses and Carnap's linguistic proposals are guided by theoretical as well as practical considerations. Now, if Quine were really aiming to undermine $I / E_{1}$, then neither of these arguments would have made sense. Since Carnap rejects $\mathrm{E}_{1^{-}}$ questions as meaningless, they are neither analytic nor synthetic; an argument against the analytic-synthetic distinction therefore has no relevance if one aims to undermine $\mathrm{I} / \mathrm{E}_{1}$. A similar conclusion can be drawn about Quine's second argument. Quine's claim that the distinction between the theoretical and the practical is a matter of degree, not kind, is not relevant had he targeted $\mathrm{I} / \mathrm{E}_{1}$, since Carnap does not view $\mathrm{E}_{1}$-questions as practical questions. ${ }^{15}$

If, on the other hand, we interpret Quine as arguing against Carnap's I/E $\mathrm{E}_{2}$ distinction, his arguments begin to make sense. For the lack of a sharp distinction between the analytic and the synthetic seriously undermines Carnap's attempt to draw a distinction between "the acceptance of a language structure and the acceptance of an assertion formulated in the language" (1950, 215). Similarly, if both scientific hypotheses and linguistic proposals are guided by theoretical as well as practical considerations, Carnap cannot uphold his claim that the two can be distinguished because I-questions are theoretical and $\mathrm{E}_{2}$-questions are practical. Quine, in this interpretation, both shows that an $\mathrm{I} / \mathrm{E}_{2}$-distinction cannot be maintained and develops a positive theory in which the distinction between the theoretical and the practical is a matter of degree.

A second reason for thinking that Quine was concerned with undermining $I / E_{2}$ instead of $\mathrm{I} / \mathrm{E}_{1}$ is the way in which he describes Carnap's external questions. In his critical papers on Carnap's distinction, Quine consistently refers to those questions as 'linguistic proposals'. In "Two Dogmas", for instance, he argues that Carnap sees ontological questions as concerned with "choosing a convenient language form, a convenient conceptual scheme or framework for science" $(1951 \mathrm{~b}, 45) .{ }^{16}$ Describing external questions in this way only makes sense if Quine has in mind Carnap's $E_{2}$-questions. $E_{1}$-questions, after all, are certainly not linguistic proposals, they are metaphysical questions concerning the reality of a certain class of entities.

Finally, my interpretation of Quine's aims in rejecting the internal-external distinction is supported by the background of the debate between Carnap and Quine. I have already noted that Carnap wrote ESO in order to respond to critical fellow empiricists who had objected that he referred to abstract objects without having shown that they "actually exist". Now, as it turns it out, Quine was one of those

\footnotetext{
15 See also Price $(2009,326)$ : "Quine's claim is that there are no purely internal issues, in Carnap's sense. No issue is ever entirely insulated from pragmatic concerns about the possible effects of revisions of the framework itself $[\ldots]$ Quine's move certainly does not restore the non-pragmatic external perspective required by metaphysics. In effect, the traditional metaphysician wants to be able to say, 'I agree it is useful to say this, but is it true?' Carnap rules out this question, and Quine does not rule it back in".

${ }^{16}$ See also Quine's (1951a, 210) and (1954a, 132), where Carnapian external questions are described as "linguistic proposal[s]" and as "matter[s] [...] of linguistic decision".
} 
critics. ${ }^{17}$ In the late 1930 s, Quine developed his criterion of ontological commitment, according to which we are committed to an entity "if and only if we regard the range of our variables as including such an entity" (1939a, 199). Carnap, who claimed to accept Quine's criterion, ${ }^{18}$ however still maintained that his talk about abstract entities should be seen as "a practical decision like the choice of an instrument” (1947, §10). From Quine's perspective, therefore, Carnap was dodging his ontological commitments. That is, although Carnap accepted Quine's "standard for judging whether a given theory accepts given alleged entities" (Quine 1951a, 205), he still did not acknowledge that he was committed to abstract objects because he viewed his "acceptance of such objects [as] a linguistic convention distinct somehow from serious views about reality (Quine 1960, 275). ${ }^{19}$

If we take this background into consideration, it becomes clear that when Quine attacked Carnap's internal-external distinction in the early 1950s, he was not concerned with the latter's claim that the traditional metaphysician's questions are devoid of cognitive content, i.e. with the claim that $\mathrm{E}_{1}$-questions are meaningless. Rather, his job was to argue that there is no proper distinction between the ontological commitments internal to a framework and the linguistic conventions upon which our framework choices are based, i.e. the distinction between I-questions on the one hand and $\mathrm{E}_{2}$-questions on the other. Indeed, when Quine first learned about the internal-external distinction in a 1949-letter from Carnap, he scribbled on the back of this letter: "When are rules really adopted? Ever? Then what application of your theory to what I am concerned with (language now)? [...] Say frameworkhood is a matter of degree, \& reconciliation ensues" (Carnap and Quine 1932-1970, 417). Whether or not this is consistent with Carnap's intentions, therefore, Quine from the very beginning interpreted Carnap's distinction as one between questions internal to a framework and questions regarding the choice of the framework itself.

In sum, Quine was not out to attack the $\mathrm{I} / \mathrm{E}_{1}$-distinction, but was concerned with undermining Carnap's $\mathrm{I} / \mathrm{E}_{2}$-distinction. Quine did not aim to restore the legitimacy of metaphysics, but rather to criticize the Carnapian view that "statements commonly thought of as ontological are proper matters of contention only in the form of linguistic proposals" (Quine 1951a, 210). ${ }^{20}$

\footnotetext{
17 In his "Intellectual Autobiography", Carnap lists Quine as one of the philosophers who rejected his way of speaking as "a 'hypostatization' of entities" (1963b, 65).

18 See Carnap $(1950,214 n 3)$.

19 Quine's discontent with Carnap's position can be traced back at least to 1937, when he, in a lecture on nominalism, suggests that although Carnap succeeds in avoiding metaphysical questions by rejecting them as meaningless, he does not "provide for reduction of all statements to statements ultimately about tangible things, matters of fact", and thereby fails to show how we can keep "our feet on the groundavoiding empty theorizing" (Quine 1937b). See Mancosu (2008, 28-29). See also Alspector-Kelly (2001, §3): “As Quine understands it, Carnap endorsed Quine's criterion of ontological commitment [...] Nonetheless, Carnap did not take himself to be committed to abstract entities, and so did not take himself to be a Platonist, despite the fact that he quantified over abstract objects. Nor did he have any plan to show that such quantification can be avoided".

${ }^{20}$ Given this misunderstanding, it is not surprising that some scholars have concluded that "Quine's criticisms leave Carnap's central points untouched" (Bird 1995, 41). For even if Carnap's central point was to distinguish between I-questions and $E_{1}$-questions-a claim that might be doubted given the
} 


\section{Quine on Metaphysical Existence Claims}

If $\mathrm{I}$ am right in claiming that Quine aims to undermine $I / E_{2}$ instead of $I / E_{1}$ in his critical papers on Carnap's internal-external distinction, then a question that remains to be answered is what $i s$ Quine's position on $\mathrm{I} / \mathrm{E}_{1}$, i.e. on the distinction between ordinary and metaphysical existence claims. After all, the claim that Quine aimed to criticize Carnap's $I / E_{2}$-distinction does not imply anything about Quine's views about the tenability of the $\mathrm{I} / \mathrm{E}_{1}$-dichotomy. In the remainder of this paper, I address this latter question.

Let me start by considering Quine's views on $\mathrm{E}_{1}$-questions. From the very beginning of his philosophical career, Quine has been sceptical about metaphysical existence claims. In one of his early (1938) letters to Carnap, for example, he already characterizes "metaphysical expressions" as "devoid of denotation, truth, and falsehood" (Carnap and Quine 1932-1970, 247-248). This attitude did not change when he developed his criterion of ontological commitment. For Quine has always made clear that his criterion is concerned with questions of existence from the point of view of a given language, or as he phrases it in "On What There Is":

We look to bound variables in connection with ontology not in order to know what there is, but in order to know what a given remark or doctrine, ours or someone else's, says there is. (Quine 1948, 15)

The traditional metaphysician's question of existence, in other words, falls outside the scope of his theory of ontological commitment. Questions about what a theory says there is, after all, are I-questions and not $\mathrm{E}_{1}$-questions. ${ }^{21}$ But whereas Carnap has always advertised his dismissal of $\mathrm{E}_{1}$-questions, Quine, in those early stages of his career, limited himself to brief remarks in his letters to Carnap ${ }^{22}$ and personal notes. ${ }^{23}$ Quine's first published remarks concerning his views about $\mathrm{E}_{1}$-questions, as we shall see shortly, are from the 1950s.

Quine's early reservations about rejecting metaphysical questions of existence are explained by the fact that he took himself to be explicating the elements of traditional metaphysics that are legitimate. Quine believed that his use of the concept 'ontology' in his theory of ontological commitment had been "nuclear to its usage all along" (1951a, 204). So although Quine, like Carnap, proposed to reinterpret the traditional metaphysician's questions, he did not, like Carnap, explicitly distance himself from the concepts used by those traditional

Footnote 20 continued

background of the Carnap-Quine debate-Quine was simply not concerned with criticizing that distinction.

21 To be more precise, questions about what a theory says there is are partly I and partly $\mathrm{E}_{2}$, according to Quine, because he believes no statement to be purely theoretical or purely practical.

22 See also, for example, Quine's letter to Carnap from May 1, 1947: "most metaphysical statements simply mean nothing to me" (Carnap and Quine 1990-1970, 410).

23 In a notebook from the early 1940s, Quine argues that although the metaphysician "should seek points outside the world that imprisons natural scientist[s] and mathematician[s]", making "himself independent of the conceptual scheme which it is his task to study and revise", this cannot be done because there simply "is no such cosmic exile" (November 5, 1944, my transcription). See my Verhaegh (forthcoming). 
metaphysicians: "meaningless words", he claimed, "are precisely the words which I feel freest to specify meanings for" (1951a, 203).

This difference in approach is illustrated by the way in which Carnap and Quine dealt with the question of nominalism. Where Carnap rejected the issue of nominalism "as meaningless because metaphysical", Quine believed that "the problem of universals [...] can be given, an important meaning" (1946, 9, my emphasis):

As a thesis in the philosophy of science, nominalism can be formulated thus: it is possible to set up a nominalistic language in which all of natural science can be expressed. The nominalist, so interpreted, claims that a language adequate to all scientific purposes can be framed in such a way that its variables admit only concrete objects, individuals, as values. (1939b, 708)

Carnap agreed that Quine's reinterpretation of nominalism "is a meaningful problem" but doubted whether it is "advisable to transfer to this new problem in logic or semantics the label "nominalism'", because the concept stems from the “old metaphysical problem" (1947, 43). Again, Carnap and Quine agreed about which types of questions are legitimate, but disagreed about whether or not those questions ought to phrased using the traditional metaphysician's concepts. ${ }^{24}$ Carnap believed it to be safer to introduce new concepts, whereas Quine wanted to emphasize that he was explicating those elements of the traditional metaphysician's question that are significant. ${ }^{25}$

So although their positions seem to differ greatly at surface level, Carnap's and Quine's views on $E_{1}$-questions were actually remarkably similar in the 1930 s and 1940s. Both dismissed metaphysical existence claims but accepted Quine's theory of ontological commitment as well as his reinterpretation of nominalism. They differed only on whether Quine's theories were to be viewed as faithful explications of the traditional metaphysician's questions. Carnap, as we have seen, proposed to "replace" them with "practical questions concerning the choice of certain language forms" (1963a, 869), whereas Quine believed that there is no $\mathrm{I} / \mathrm{E}_{2}$-distinction and hence proposed to replace them by questions about "the ontological commitments of a given doctrine or body of theory" (1951a, 203). That is, Carnap and Quine agreed that $\mathrm{E}_{1}$-questions ought to be rejected but differed about whether to reinterpret those questions as either I-questions (like Quine) or as purely $\mathrm{E}_{2^{-}}$ questions (like Carnap). ${ }^{26}$ Quine's reticence to be explicit about his views on $\mathrm{E}_{1^{-}}$ questions has probably contributed significantly to the misunderstanding that he was aiming to restore the intelligibility of metaphysical existence claims.

\footnotetext{
24 Cf. Alspector-Kelly (Alspector-Kelly 2001, §7).

25 See also, for example, Quine's letter to Carnap from January 5, 1943, in which Quine talks about there being a "kernel of technical meaning in the old controversy about reality or irreality of universals" (Carnap and Quine 1990-1970, 295). Somewhat related, in 1947 Goodman and Quine published their joint paper "Steps towards a Constructive Nominalism" (1947). When Goodman proposed to dub the joint position he and Quine defended 'particularism', Quine argued in a letter (June 12, 1947) that they should stick with 'nominalism' because it is "a shame to disavow a noble tradition when we are squarely in line with it" (Quine and Goodman 1935-1994). See also Mancosu (2008, 42).

26 But see footnote 21 .
} 
In later work, however, Quine did become more explicit about the difference between his views on ontology and the questions asked by traditional metaphysicians. He came to accept that Carnap was right in claiming that philosophers who treat questions of existence "as a serious philosophical problem [...] do not have in mind the internal question" (Carnap 1950, 209). That is, he explicitly recognized that there are two ways to understand questions of existence, an ordinary one (e.g. "Are there numbers?") and a philosophical one (e.g. "Are there really numbers?"). The traditional metaphysician, Quine argued, is not interested in questions of ontological commitment but rather wants to "inquire into the absolute correctness of a conceptual scheme", wants to answer "[t]he fundamental seeming philosophical question, How much of our science is merely contributed by language and how much is a genuine reflection of reality?" (1950, 78-79), wants to know "what reality is really like" (1992, 405), or, in Kantian terms, "whether or in how far our science measures up to the Ding an Sich" $(1981,22)$. In response to these questions, Quine now explicitly argues against traditional metaphysics. According to Quine, any inquiry into the absolute correctness of a conceptual scheme is "meaningless" $(1950,79)$ and any question about what reality is really like is "self-stultifying" (1992, 405) and senseless $(1981,22)$.

Yet, not only did Quine become more explicit about his position with respect to $\mathrm{E}_{1}$-questions, he also started to develop an argument against them. And just as his views on $\mathrm{E}_{1}$-questions are similar to Carnap's, his argument against those questions is in Carnapian spirit as well. As we have seen, Carnap's argument against $\mathrm{E}_{1^{-}}$ questions relies on the idea that the very concept of 'reality', which plays an important role in the metaphysician's question about whether a certain object really exists, cannot be meaningfully applied outside the framework of which it is an element. If we now replace Carnap's talk about frameworks with Quine's holistic picture of science as a "man-made fabric which impinges on experience only along the edges" (1951b, 42), we get a very similar argument. In the early 1950s, Quine starts to argue that key philosophical concepts like 'reality' cannot be divorced from their everyday scientific applications. When the traditional metaphysician asks us what reality is really like, Quine argues, she "dissociate[s] the [term] 'reality' [...] from the very applications which originally did most to invest those terms with whatever intelligibility they may have for us" (1954b, 229). ${ }^{27}$ According to Quine, "[t]here is no deeper sense of 'reality' than the sense in which it is the business of science itself, [...] to seek the essence of reality" $(1996,348)$. When the traditional metaphysician asks us about the true nature of reality, in other words, she presupposes that we can separate the term 'reality' from its ordinary scientific use. According to Quine, however, this cannot be done.

\footnotetext{
27 This argument first occurs in Quine's "On Mental Entities", where he speaks about "the ordinary usage of the word 'real'” (1952, 225). See also my Verhaegh (2014).
} 


\section{Scientific Sense and Metaphysical Nonsense}

Let me sum up what we have established thus far. I have argued that we ought to distinguish between two types of internal-external distinctions: $I / E_{1}$ and $I / E_{2}$. Quine should not be viewed as aiming to attack $\mathrm{I} / \mathrm{E}_{1}$, thereby breathing new life into the metaphysical project that was deemed meaningless by Carnap, because he was solely concerned with undermining $I / E_{2}$. In fact, Quine's perspective on $\mathrm{E}_{1^{-}}$ questions, even in the early stages of his career, is remarkably similar to Carnap's. For although Carnap and Quine disagree about how to reinterpret $\mathrm{E}_{1}$-questions, they both reject these questions and use similar arguments to show why they ought to be dismissed.

In the light of these facts, one might conclude that Quine is committed to an $I / E_{1}$ distinction himself. That is, one might conclude that Quine too is committed to a distinction between scientific sense and metaphysical nonsense. ${ }^{28}$ This would be a too hasty conclusion, however, as Quine has always maintained that he is "blurring [...] the boundary" between "natural science" and the "philosophical effusions that Carnap denounced under the name of metaphysics" as well (1984, 127-128). ${ }^{29}$

How can this be? How can Quine both dismiss metaphysical existence claims and at the same time reject Carnap's distinction between science and traditional metaphysics? I believe that the answer can be found in Quine's rejection of the criterion of significance that underlies Carnap's distinction. For although Quine sometimes uses the term 'meaningless' in dismissing metaphysics, ${ }^{30}$ there is ample evidence that he does not, like Carnap, subscribe to a strict, philosophically potent distinction between the meaningful and the meaningless. In From Stimulus to Science, for example, Quine explicitly dismisses the positivistic thesis that a sentence "is meaningless unless it has empirical content" $(1995,48)$. Because of his holistic view that no single statement has "distinctive content of its own" (1984, 125-126), Quine argues, no strict criterion of empirical content can be drawn. Against the suggestion that a sentence $q$ has empirical content if and only if it is a supporting member of a set of sentences $Q$ with critical mass such that if $q$ is withdrawn it deprives $Q$ of empirical content, for example, he argues that on this criterion any sentence whatsoever will have empirical content trivially:

Any sentence, even Russell's 'Quadruplicity drinks procrastination', is a supporting member of a set that implies an observation categorical. Let us abbreviate Russell's sentence as ' $q$ ', and some observational categorical as ' $c$ '. The two-member set $\{$ ' $q$ ', ' $q \supset c$ ' $\}$ implies ' $c$ ', but the one-member set

\footnotetext{
${ }^{28}$ Indeed, I used to think this myself. See Verhaegh (2015), in which I argue that Quine himself presupposes something like an $\mathrm{I} / \mathrm{E}_{1}$-distinction in his disquotational theories of truth and reference. I am greatly indebted to Peter Hylton and Gary Ebbs for pressing some of the issues discussed in the present section, which has led me to conclude differently.

29 See also Quine (1951b, 20), where he speaks about "a blurring of the supposed boundary between speculative metaphysics and natural science" and (1987a, 144), where he dismisses the "boundary between scientific sense and metaphysical nonsense" as "dubious".

${ }^{30}$ For instance, when he claims that the "[p]ositivists were right in branding [...] metaphysics as meaningless" (1992, 405).
} 
$\{$ ' $q \supset c$ ' $\}$ does not. So Russell's sentence is a supporting member of $\{$ ' $q$ ', ' $\left.q \supset c^{\prime}\right\}(1995,48)$.

Quine, in other words, knows no way to strictly distinguish between statements with and statements without empirical content. More important given our purposes here, however, is that Quine insists that even if it were possible to draw such a strict distinction, he would not want employ it as a distinction between the meaningful and the meaningless. For even statements that are completely without empirical content, Quine argues, should not be dismissed as meaningless:

Even if I had a satisfactory notion of shared content, I would not want to impose it in a positivist spirit as a condition of meaningfulness. Much that is accepted as true or plausible in the hard sciences, I expect, is accepted without thought of its joining forces with other plausible hypotheses to form a testable set [...] Positivistic insistence on empirical content could, if heeded, impede the progress of science (Ibid., 48-49).

Quine, in sum, cannot dismiss metaphysical existence claims as meaningless, because he does not subscribe to a philosophically interesting criterion of significance at all. ${ }^{31}$

On what grounds, then, does Quine dismiss metaphysical existence claims? The answer is surprisingly simple. As early as 1937, Quine provides a solution to this question in one of his notebooks; metaphysical existence claims are not meaningless, they are merely useless from a scientific perspective:

Meaninglessness must be abandoned as meaningless-at least insofar as it might be used against metaphysics. Even supposing we would make sense ultimately of an operational criterion, this would rule out all the nonintuitionistic part of math[ematics] also. But we keep latter, because useful algorithmically for science. We discard metaphysics because useless for science. If part of met[aphysics] became useful for science, we might use it on same grounds as non-constructive math[ematics]. (Quine 1937a, my transcription)

This idea that metaphysical existence claims are not meaningless but useless for science is something Quine held on to until the end of his career. In his unpublished Notre Dame Lectures, for instance, Quine argues that although metaphysical questions are "technically meaningful", they are "pragmatically empty and need not arise" (1970, 12-13, my transcription). Similarly, in his 1986 paper "The Way the World Is", Quine proposes that portions of science without empirical content (e.g. higher set theory) should be accepted as meaningful because they "deal with questions that can be formulated in the same vocabulary and the same idioms that are also useful, in other combinations, elsewhere in science". He is not willing, however, to grant metaphysics a similar position: "There are further reaches of discourse [...] for which not even these claims to a scientific status can be made. One thinks here of bad metaphysics" (1986a, 169, my emphasis). Presumably the

\footnotetext{
31 For a more extensive argument for the thesis that "there is simply no idea of nonsense that is defensible in Quinean terms which will play an significant philosophical role”, see Hylton (2014).
} 
reason is precisely that metaphysics cannot 'be formulated in the same vocabulary' as science, because the metaphysician appeals to concepts that are divorced from their everyday scientific applications. The traditional metaphysician's concepts, in other words, are scientifically useless because in asking us about the true nature of reality, she separates the term 'reality' from its ordinary scientific use. For Quine, asking what reality is really like independently of our scientific system of the world is "like asking how long the Nile really is, apart from parochial notions of miles or meters" $(1992,405)$. Just like our notion of 'length' is useless if it is divorced from related notions like 'mile' and 'meter' and some standards of measurement, our notion of 'reality' is useless when one purports to use it in a way that is divorced from our theory of the world and our scientific standards.

Quine, in conclusion, can both dismiss metaphysical existence claims and, at the same time, reject Carnap's strict distinction between science and metaphysics because he, unlike Carnap, refuses to appeal to a strict criterion of significance. Where Carnap requires a "metalinguistic tool" to distinguish between "the meaningful claims of science and the meaningless claims of metaphysics" (Ebbs 2011, 198), Quine argues that we can get rid of metaphysical existence claims without dismissing them as meaningless. In other words, where Carnap's metaphysical deflationism is still "a characteristically philosophical form of deflationism" because he chooses not to "leave philosophy behind in favor of the standpoint of the 'working scientist'" (Friedman 1999, 214-215), Quine's naturalism entails that "we own and use our beliefs of the moment, even in the midst of philosophizing" (1960, 24-25). This implies that Quine does not require an external criterion to get rid of metaphysical existence claims; for from "within our total evolving doctrine" (ibid. 25), we simply have no use for metaphysical hypotheses. $^{32}$

\section{Conclusion}

Carnap's 'Empiricism, Semantics, and Ontology' contains two internal-external distinctions: one between scientific sense and metaphysical nonsense and one between questions internal to a framework and questions regarding the choice of the framework itself. I have argued that although Quine dismisses both distinctionsthe former because there is no strict philosophically potent criterion of significance, the latter because there is no strict distinction between the theoretical and the practical-we should not interpret Quine as reviving the metaphysics that was deemed meaningless by Carnap. For although Quine does not reject metaphysics as meaningless, he dismisses metaphysical existence claims because they are useless from a scientific point of view. In one sense, therefore, Quine and Carnap "are playing for the same team" (Price 2009, 323n1). In another sense, however, they are not. For in blurring the "supposed boundary between speculative metaphysics and

\footnotetext{
32 Indeed, in a set of notes for a conference in Oberwolfach, Quine explains his position by referring to Pierre-Simon Laplace's famous reply to Napoleon about the existence of God: "What of mngless. of metaphysics? Well, just danglers, not contributing to joint implications of observ'n. 'Je n'ai pas besoin de cette hypothèse"' (1987b, my transcription).
} 
natural science" (1951b, 20), Quine has effectively shown that we can get rid of metaphysics without relying on an external criterion to distinguish between what can and what cannot be meaningfully said. Where Carnap has always been actively concerned with developing a definitive weapon against traditional metaphysics, refusing even to use the traditional metaphysicians' concepts when reinterpreted, Quine was not especially worried about metaphysics. Quine dealt with metaphysical existence claims like he dealt with all false statements: he simply dismissed them from within.

Acknowledgments I would like to thank Peter Hylton, Gary Ebbs, Hans-Johann Glock, Lieven Decock, Jeanne Peijnenburg, Allard Tamminga, and the anonymous referees for this Journal for their valuable comments on earlier drafts of this paper. Early drafts of this paper have been presented at the VAF conference in Groningen, the OZSW conference in Rotterdam, and the MetaMetaphysical Club in Rotterdam. I would like to thank the audiences at these conferences for their valuable suggestions. This research is funded by the Netherlands Organization for Scientific Research (NWO), Grant 322-20-001.

Open Access This article is distributed under the terms of the Creative Commons Attribution 4.0 International License (http://creativecommons.org/licenses/by/4.0/), which permits unrestricted use, distribution, and reproduction in any medium, provided you give appropriate credit to the original author(s) and the source, provide a link to the Creative Commons license, and indicate if changes were made.

\section{References}

Alspector-Kelly, M. (2001). On Quine on Carnap on ontology. Philosophical Studies, 102(1), 93-122.

Berto, F., \& Plebani, F. (2015). Ontology and metaontology: A contemporary guide. London: Bloomsbury.

Bird, G. (1995). Carnap and Quine: Internal and external questions. Erkenntnis, 42(1), 41-64.

Carnap, R. (1928). Scheinprobleme in der Philosophie. Berlin, Schlachtensee: Weltkreis. Pseudoproblems in Philosophy (trans: George, R.). Berkeley: University of California Press (1967).

Carnap, R. (1934). Logische Syntax der Sprache. The logical syntax of language (trans. Smeaton A.). London: Routledge \& Kegan Paul, Trench, Trubner \& Co.

Carnap, R. (1947). Meaning and necessity: A study in semantics and modal logic. Enlarged edition (1956). University of Chicago Press, Chicago.

Carnap, R. (1950). Empiricism, semantics, and ontology. Revue Internationale de Philosophie, 4(11):20-40. Reprinted in Carnap (1947), pp. 205-221.

Carnap, R. (1963a). Intellectual autobiography. In Schilpp (1963), pp. 3-84.

Carnap, R. (1963b). Replies and systematic expositions. In Schilpp (1963), pp. 859-1013.

Carnap, R., \& Quine, W. V. (1932-1970). The Quine-Carnap correspondence. In Creath (1990), Dear Carnap, Dear Van. University of California Press, Berkeley, pp. 105-425.

Ebbs, G. (2011). Carnap and Quine on truth by convention. Mind, 120(478), 193-237.

Eklund, M. (2013). Carnap's metaontology. Noûs, 47(2), 229-249.

Friedman, M. (1999). Tolerance and analyticity in Carnap's philosophy of mathematics. In Friedman. Reconsidering logical positivism. Cambridge: Cambridge University Press, pp. 198-233.

Gallois, A. (1998). Does ontology rest on a mistake? Proceedings of the Aristotelian Society Supplementary, 72(1), 263-283.

Glock, H. J. (2002). Does ontology exist? Philosophy, 77(2), 235-260.

Goodman, N., \& Quine, W. V. (1947). Steps towards a constructive nominalism. Journal of Symbolic Logic, 12(4), 105-122.

Haack, S. (1976). Some preliminaries to ontology. Journal of Philosophical Logic, 5(4), 457-474.

Hylton, P. (2014). Significance in Quine. Grazer Philosophische Studien, 89(1), 1-21. 
Joll, N. (2010). Contemporary metaphilosophy. Internet Encyclopedia of Philosophy. http://www.iep.utm. edu/con-meta/. Last accessed: December 2015.

Mancosu, P. (2008). Quine and Tarski on nominalism. In Zimmerman (2008), pp. 22-55.

Price, H. (2007). Quining naturalism. The Journal of Philosophy, 104(8), 375-402.

Price, H. (2009). Metaphysics after Carnap: The ghost who walks? In D. Chalmers, D. Manley, \& R. Wasserman (Eds.), Metametaphysics: New essays on the foundations of ontology (pp. 320-346). Oxford: Oxford University Press.

Quine, W. V. (1937a). A pragmatic interpretation of positivism. Unpublished Autograph Notes, W. V. Quine Papers (MS Am 2587): Box 108, Item 3169. Houghton Library, Harvard University.

Quine, W. V. (1937b). Nominalism. Unpublished autograph manuscript. W. V. Quine Papers (MS Am 2587): Box 103, Item 2969. Houghton Library, Harvard University.

Quine, W. V. (1939a). A logistical approach to the ontological problem. In Quine (1966), pp. 197-202.

Quine, W. V. (1939b). Designation and existence. The Journal of Philosophy, 36(26), 701-709.

Quine, W. V. (1944). Ontology notes. Unpublished autograph notes, November 5, 1944. W. V. Quine Papers (MS Am 2587): Box 108, Item 3181. Houghton Library, Harvard University.

Quine, W. V. (1946). Nominalism. Lecture transcribed by P. Mancosu. In Zimmerman (2008), pp. 3-21. Quine, W. V. (1948). On what there is. In Quine (1953), pp. 1-19.

Quine, W. V. (1950). Identity, ostension, hypostasis. In Quine (1953), pp. 65-79.

Quine, W. V. (1951a). On Carnap's views on ontology. In Quine (1966), pp. 197-202.

Quine, W. V. (1951b). Two dogmas of empiricism. In Quine (1953), pp. 20-46.

Quine, W. V. (1952). On mental entities. In Quine (1966), pp. 221-227.

Quine, W. V. (1953). From a logical point of view. Revised edition (1961). Cambridge, MA: Harvard University Press.

Quine, W. V. (1954a). Carnap and logical truth. In Quine (1966), pp. 107-132.

Quine, W. V. (1954b). The scope and language of science. In Quine (1966), pp. 228-245.

Quine, W. V. (1960). Word and object. Cambridge, MA: The M.I.T Press.

Quine, W. V. (1966). The ways of paradox and other essays. Random House, New York. Revised edition (1976). Cambridge, MA: Harvard University Press.

Quine, W. V. (1968). Existence and quantification. In Quine (1969), pp. 91-113.

Quine, W. V. (1969). Ontological relativity and other essays. New York: Columbia University Press.

Quine, W. V. (1970). The Notre Dame lectures. Unpublished autograph manuscript. W. V. Quine Papers (MS Am 2587): Box 103, Item 2971. Houghton Library, Harvard University.

Quine, W. V. (1981). Things and their place in theories. In Theories and things (pp. 1-23). Cambridge, MA: Harvard University Press.

Quine, W. V. (1984). Carnap's Positivistic Travail. In Quine (2008b), pp. 119-128.

Quine, W. V. (1986a). The way the world is. In Quine (2008a), pp. 166-171.

Quine, W. V. (1986b). The sensory support of science. In Quine (2008a), pp. 327-337.

Quine, W. V. (1987a). Carnap. In Quine (2008b), pp. 142-145.

Quine, W. V. (1987b). Holism. Unpublished autograph manuscript. W. V. Quine Papers (MS Am 2587): Box 102, Item 2928. Houghton Library, Harvard University.

Quine, W. V. (1992). Structure and nature. In Quine (2008a), pp. 401-406.

Quine, W. V. (1995). From stimulus to science. Cambridge, MA: Harvard University Press.

Quine, W. V. (1996). Quine/'kwain/, Willard Van Orman (b. 1908). In Quine (2008b), pp. 461-472.

Quine, W. V. (2008a). Confessions of a confirmed extensionalist and other essays. Edited by Føllesdal, D. and D. B. Quine. Harvard University Press, Cambridge, MA.

Quine, W. V. (2008b). Quine in dialogue. Edited by Føllesdal, D. and D. B. Quine. Harvard University Press, Cambridge, MA.

Quine, W. V., \& Goodman, N. (1935-1994). The Quine-Goodman correspondence. W. V. Quine Papers (MS Am 2587): Box 016, Item 420. Houghton Library, Harvard University.

Schilpp, P. (Ed.) (1963). The philosophy of Rudolf Carnap. The Library of Living Philosophers. Volume XI. Open Court, La Salle, Ill.

Stroll, A. (2000). Twentieth-century analytic philosophy. New York: Columbia University Press.

Verhaegh, S. (2014). Quine's argument from despair. British Journal for the History of Philosophy, 22(1), $150-173$.

Verhaegh, S. (2015). Rafts, boats, and cruise ships: Naturalism and holism in Quine's philosophy. Ph.D. Dissertation, University of Groningen.

Verhaegh, S. (forthcoming). Boarding Neurath's boat: The early development of Quine's naturalism. Journal of the History of Philosophy. 
Yablo, S. (1998). Does ontology rest on a mistake? Proceedings of the Aristotelian Society Supplementary, 72(1), 229-261.

Zimmerman, D. (Ed.). (2008). Oxford studies in metaphysics (Vol. 4). Oxford: Oxford University Press. 